\title{
Hemodynamic effects of doxycycline combined with adrenomedullin during acute pulmonary embolism- induced pulmonary hypertension
}

\author{
Thalita L A Rocha ${ }^{1}$ and Carlos A Dias-Junior ${ }^{1,2 *}$ \\ ${ }^{1}$ Department of Anesthesiology, School of Medicine of Botucatu, Sao Paulo State University, UNESP, Botucatu, Sao Paulo, Brazil \\ ${ }^{2}$ Department of Pharmacology, Institute of Biosciences of Botucatu, Sao Paulo State University, UNESP, Botucatu, Sao Paulo, Brazil
}

\begin{abstract}
Matrix metalloproteinases (MMPs) may limit severely the pulmonary vasodilatory and inotropic effects of adrenomedullin during pulmonary hypertension. While doxycycline inhibits MMPs and prevents the hemodynamic disorders associated with acute pulmonary embolism (APE), no previous study evaluated if doxycycline enhances adrenomedullin-induced pulmonary vasodilation and contributes to the attenuation of APE-induced pulmonary hypertension. Hemodynamic and respiratory changes were determined in animals not subjected to any intervention (Sham group), or animals subjected to APE induced by microspheres treated with saline (PE group) or $10 \mathrm{mg} / \mathrm{kg}$ of doxycycline (Dox+PE group) $30 \mathrm{~min}$ before APE or $50 \mathrm{ng} / \mathrm{kg} / \mathrm{min}$ of adrenomedullin (PE+Adm group) 30 after APE, or doxycycline combined with adrenomedullin (Dox $+\mathrm{PE}+\mathrm{Adm}$ group). Doxycycline produced no effect on significant temporal decreases in pulmonary vascular resistance index and increases in cardiac index (both by 25\%) observed with adrenomedullin. Adrenomedullin produced moderate systemic hypotension. Significant decreases in arterial oxygen partial pressure were observed after doxycycline or APE, but these changes were not affected by adrenomedullin. These results show that the combined administration of doxycycline and adrenomedullin is not advantageous compared with adrenomedullin alone, thus suggesting that adrenomedullin counteracted the pulmonary vasoconstriction and it may help in the therapy of the detrimental acute hemodynamic consequences of APE.
\end{abstract}

\section{Introduction}

Pulmonary circulation has a key role in filtering thrombi present in the deep venous system, which are the most common source of embolus to the lungs, causing acute pulmonary embolism (APE). APEinduced pulmonary hypertension leading to acute right heart failure and circulatory shock are important causes of morbidity and death [13].

The usual therapy of APE includes supportive care, systemic anticoagulation, systemic thrombolysis and surgical embolectomy [4]. While the current treatment of APE targets the mechanical obstruction, recent studies have highlighted the relevance of pulmonary arterial vasoconstriction immediately after APE is installed [5]. However, few studies have addressed the hypothesis that the combination of drugs that attenuate the pulmonary hypertension and that improve the cardiac output during APE may produce complementary and beneficial effects than might enhance survival of APE [6].

Previous study demonstrated that adrenomedullin $(50 \mathrm{ng} / \mathrm{kg} /$ $\mathrm{min}$ ) intravenously administrated induced a long-lasting reduction of pulmonary vascular resistance and improved cardiac index (both by $50 \%$ ) after pulmonary hypertension induced by endotoxin in sheep [7]. Furthermore, the same dose of adrenomedullin (for 30 minutes) in patients with pulmonary hypertension greatly increased cardiac index by $44 \%$ and that resulted in a $32 \%$ decrease in pulmonary vascular resistance [8-10]. Recently, we also showed adrenomedullin significantly decreased pulmonary vascular resistance and increased cardiac index, both by 25\% [11] after APE-induced pulmonary hypertension in anaesthetized sheep. Notably, adrenomedullin treatment resulted in a significant attenuation of pulmonary hypertension without impacting on systemic blood pressure, heart rate and global oxygen transport $[7,9,11]$. Therefore, it appears that the current literature supports the hypothesis that adrenomedullin may be a therapeutic agent with inotropic and pulmonary vasodilatory effects after APE, being a promising adjunct in the therapeutic approach targeting the treatment of acute pulmonary hypertension, independent of its pathogenesis $[8,12-14]$.

Interestingly, previous studies have shown that adrenomedullin may be degraded by matrix metalloproteinases (MMPs), resulting in smaller peptides that promote vasoconstriction, thereby inhibiting the hypotensive effect adrenomedullin dependent [15]. Accordingly, the MMPs inhibition with doxycycline prevented both decreases in circulating adrenomedullin and hypertension in rats [16]. Additionally, the up-regulation of MMPs has also been involved in the development of APE-induced pulmonary hypertension [17-19], since the MMPs inhibition with doxycycline produced beneficial effects on the hemodynamic derangements associated with APE [20]. Supporting these findings, the activation of MMPs in pulmonary vessels and in

Correspondence to: Carlos A. Dias-Junior, Pharm D, PhD, Department of Pharmacology, Biosciences Institute of Botucatu, Sao Paulo State University, Distrito de Rubiao Junior, S/N, 18.618-970 Botucatu, SP, Brazil; E-mail: carlosjunior@ibb.unesp.br

Key words: adrenomedullin, matrix metalloproteinases, pulmonary embolism, pulmonary hypertension

Received: February 06, 2016; Accepted: March 02, 2016; Published: March 05, 2016 
the right ventricle may contribute to the pulmonary vasoconstriction and to the decreased inotropic activity in the setting of APE, causing myocardial contractile dysfunction [21-24].

Together, the above-mentioned studies support the hypothesis that increased MMPs activity may be limiting severely the pulmonary vasodilatory and impair the inotropic effects of adrenomedullin during APE. However, no previous study has examined whether doxycycline enhance the pulmonary vasodilatory and positive inotropic effects produced by adrenomedullin during APE [11].

\section{Methods}

\section{Animal model and cardiopulmonary hemodynamic measurements}

The study complied with guidelines of the Institutional Animal Care Committee (protocol $n^{\circ} 457 / 2013$ ) and the animals were handled according to the guidelines published by the European Union Directive (2010/63/EU) and the ARRIVE (Animal Research: Reporting of In Vivo Experiments). We used a whole animal model of APE [25] to study the hemodynamic effect of intravenous (i.v.) doxycycline combined with i.v. adrenomedullin on APE-induced hemodynamic changes. Sixteen rams of the Santa Inês breed $(36.3 \pm 3.1 \mathrm{~kg})$ received fentanyl $(5 \mu \mathrm{g} /$ $\mathrm{kg}$, i.v.) before anesthesia was induced and maintained with ketamine $(7.5 \mathrm{mg} / \mathrm{kg}$, i.v. bolus, followed by $20 \mathrm{mg} / \mathrm{kg} / \mathrm{h}$, i.v. $)$ and midazolam $(0.35 \mathrm{mg} / \mathrm{kg}$ bolus i.v., followed by $0.25 \mathrm{mg} / \mathrm{kg} / \mathrm{h}$, i.v. $)$. Their lungs were mechanically ventilated with an inspired $\mathrm{O}_{2}$ fraction $>0.9$ (Dräger Primus, Drägerwerk AG \& Co, Lübeck, Germany) during conditions of neuromuscular blockade produced by atracurium $(0.3 \mathrm{mg} / \mathrm{kg}$, followed by $0.5 \mathrm{mg} / \mathrm{kg} / \mathrm{h}$, i.v.). The tidal volume and the inspiration-toexpiration ratio were held constant throughout the study $(15 \mathrm{ml} / \mathrm{kg}$ and $1: 2$, respectively), while the respiratory rate was adjusted as necessary to maintain eucapnia $\left(\mathrm{PaCO}_{2}\right.$ between 35 to $\left.45 \mathrm{mmHg}\right)$.

A 20-gauge catheter (Insyte, Becton Dickinson, Sao Paulo, Brazil) was placed into a cephalic vein for drug injection and Lactated Ringer's administration $(2 \mathrm{~mL} / \mathrm{kg} / \mathrm{h})$. The femoral artery was catheterized with an 18-gauge for monitoring mean arterial pressure via a fluid-filled pressure transducer system (Tru Wave PX 260, Edward Lifesciences, Irvine, CA) and for collecting samples in heparinized syringes for temperature corrected blood gas analysis ( $348 \mathrm{pH}$ Blood Gas Analyzer, Siemens, Halstead, UK).

A fluid-filled 7.5F balloon-tipped Swan-Ganz thermodilution catheter (Model 131HF7, Edwards Lifesciences, Irvine, CA) was inserted into the jugular vein through an $8.5 \mathrm{Fr}$ introducer sheath and advanced until its tip reached the pulmonary artery based on the observations of pressure waveforms on the screen of a monitor (AS/3, Datex Ëngstrom, Helsinki, Finland). The proximal and distal ports of the catheter were connected to two pressure transducers to allow monitoring of central venous and pulmonary artery pressures, respectively. The pulmonary artery occlusion pressure was measured by temporarily insufflating the balloon of the catheter with $0.7 \mathrm{ml}$ of air. Transducers were zeroed at the heart level before beginning the hemodynamic assessments.

Cardiac output was measured in triplicate by injecting $5 \mathrm{~mL}$ of cold $\left(3-5^{\circ} \mathrm{C}\right) 5 \%$ dextrose solution into the central venous pressure port and heart rate was calculated by the electrocardiogram. Cardiac index, pulmonary and systemic vascular resistance indexes were calculated using standard formulae. Heart rate was monitored by a lead II electrocardiogram.
Arterial blood samples were drawn from the femoral artery catheter for measuring temperature-corrected $\mathrm{pH}$, carbon dioxide partial pressure $\left(\mathrm{PaCO}_{2}\right)$, and oxygen partial pressure $\left(\mathrm{PaO}_{2}\right)(348 \mathrm{pH}$ Blood Gas Analyzer, Siemens, Halstead, UK).

\section{Study design and data collection}

The animals were randomly assigned to two experimental groups ( $\mathrm{n}=8$ per group) as follows:

1) Dox + PE group: sheep that received doxycycline $(10 \mathrm{mg} / \mathrm{kg}$, i.v. during $10 \mathrm{~min}$; [23]) followed $30 \mathrm{~min}$ later by APE induced by injection of silicone microspheres $(10 \mathrm{mg} / \mathrm{mL}$, Sephadex G50; Pharmacia Fine Chemicals; Uppsala, Sweden) as described previously [11] and $60 \mathrm{~min}$ later an infusion of physiological saline (placebo) maintained for 30 min (Pump 11 Elite, Harvard Apparatus, Holliston, MA).

2) Dox+PE+Adm group: sheep that received doxycycline (same dose as the Dox+PE group) followed 30 min later by APE, and $60 \mathrm{~min}$ later by an infusion of adrenomedullin ( $50 \mathrm{ng} / \mathrm{kg} / \mathrm{min}$, i.v. [7]) (Human Adrenomedullin, Bachem AG, Bubendorf, Switzerland) maintained for 30 min (Pump 11 Elite).

Baseline measurements $(\mathrm{BL})$ were recorded and doxycyline was injected 30 minutes before APE induction. Measurements were performed 15 and $30 \mathrm{~min}$ after doxycycline injection $\left(\right.$ Dox $_{15}$ and Dox $_{30}$, respectively). Immediately after the Dox ${ }_{30}$ time point, animals received the microspheres and data was collected 15 and $30 \mathrm{~min}$ after induction of pulmonary embolism ( $\mathrm{PE}_{15}$ and $\mathrm{PE}_{30}$, respectively). In the Dox+PE+Adm group, 30 minutes after induction of APE, an intravenous adrenomedullin infusion $(50 \mathrm{ng} / \mathrm{kg} / \mathrm{min})$ was maintained for $30 \mathrm{~min}$ and data was recorded 15 and $30 \mathrm{~min}$ after commencing the adrenomedullin infusion ( $\mathrm{Adm}_{15}$ and $\mathrm{Adm}_{30}$ time points, respectively); while in the Dox $+\mathrm{PE}$ group, an equal volume of physiological saline was administered as placebo. Post-treatment data was recorded 15 and $30 \mathrm{~min}$ after the adrenomedullin or the placebo infusion were stopped $\left(\mathrm{PT}_{15}\right.$ and $\mathrm{PT}_{30}$, respectively).

To avoid unnecessary use of animals, the data obtained in this study were compared with previously published data from our laboratory performed under the same experimental conditions evaluating the effects of adrenomedullin using the same model of microsphereinduced APE [11]:

1) Sham group, non-embolized sheep that did not receive any intervention;

2) PE group, sheep that underwent APE induced by microspheres, followed $30 \mathrm{~min}$ later by placebo.

3) $\mathrm{PE}+\mathrm{Adm}$ group, animals where a $30 \mathrm{~min}$ infusion of adrenomedullin (Human Adrenomedullin, Bachem AG, Bubendorf, Switzerland) was administered $30 \mathrm{~min}$ after induction of APE.

In the Sham, $\mathrm{PE}$, and $\mathrm{PE}+\mathrm{Adm}$ groups data recording were initiated from the moment recorded immediately before induction of APE $\left(\right.$ Dox $\left._{30}\right)$; the remaining data collection times coincided with the time points described previously. Compared to these groups, cardiopulmonary evaluations in the Dox $+\mathrm{PE}$ and Dox $+\mathrm{PE}+\mathrm{Adm}$ groups were performed for an additional 30 and 15 minutes before the APE induction (BL and Dox $_{15}$, respectively).

After the end of data collection, a lethal dose of sodium thiopental $(30 \mathrm{mg} / \mathrm{kg})$ combined with potassium chloride $(150 \mathrm{mg} / \mathrm{kg})$ were administered i.v. while the animals were still anesthetized. 


\section{Statistical analysis}

A Shapiro-Wilk test was applied to verify normality of data distribution. Two-way analysis of variance (ANOVA) for repeated measures (with time and treatment defined as main effects) followed by the Dunnett's multiple comparisons test (Prism 6.02; Graph Pad, San Diego, CA) for between and within group comparisons. Differences between groups were evaluated in relation to the PE group. Data obtained in within each group were compared with the $\mathrm{PE}_{30}$ time point as a reference. A type I error rate $<0.05$ was considered statistically significant. All the results are expressed as means \pm S.E.M.

\section{Results}

Sham animals presented significantly lower pulmonary vascular resistance index and mean pulmonary artery pressure than corresponding values recorded after microsphere injection in the PE group. Doxycycline injection alone increased pulmonary vascular resistance index and mean pulmonary artery pressure and these pulmonary parameters recorded $30 \mathrm{~min}$ after doxycycline injection $\left(\right.$ Dox $\left._{30}\right)$ in doxycycline treated groups were significantly higher in comparison to same time point recorded in the PE group, when embolized controls did not receive any treatment (Figure 1).

The pulmonary vascular resistance index and mean pulmonary artery pressure values recorded at $\mathrm{BL}$ in Dox $+\mathrm{PE}$ and Dox $+\mathrm{PE}+\mathrm{Adm}$ groups were significantly lower than corresponding values recorded 30 min after APE $\left(\mathrm{PE}_{30}\right)$; while values recorded at $\mathrm{Dox}_{15}$ and $\mathrm{Dox}_{30}$ in both groups that received doxycycline did not differ from $\mathrm{PE}_{30}$, with the exception of the $\mathrm{Dox}_{30}$ time point in the Dox $+\mathrm{PE}+\mathrm{Adm}$ group, when mean pulmonary artery pressure at $\operatorname{Dox}_{30}$ was $25 \%$ lower than the corresponding value recorded at $\mathrm{PE}_{30}$ (Figure 1).

Treatment with adrenomedullin significantly decreased pulmonary vascular resistance index and significantly increased cardiac index in comparison to $\mathrm{PE}_{30}$, without causing significant temporal effects on mean pulmonary artery pressure. The Dox $+\mathrm{PE}$ and Dox $+\mathrm{PE}+\mathrm{Adm}$ groups showed no further changes in pulmonary vascular resistance index and mean pulmonary artery pressure in comparison to the $\mathrm{PE}_{30}$ time point. In the $\mathrm{PE}+\mathrm{Adm}$ and $\mathrm{Dox}+\mathrm{PE}+\mathrm{Adm}$ groups there were no differences in pulmonary vascular resistance index, mean pulmonary

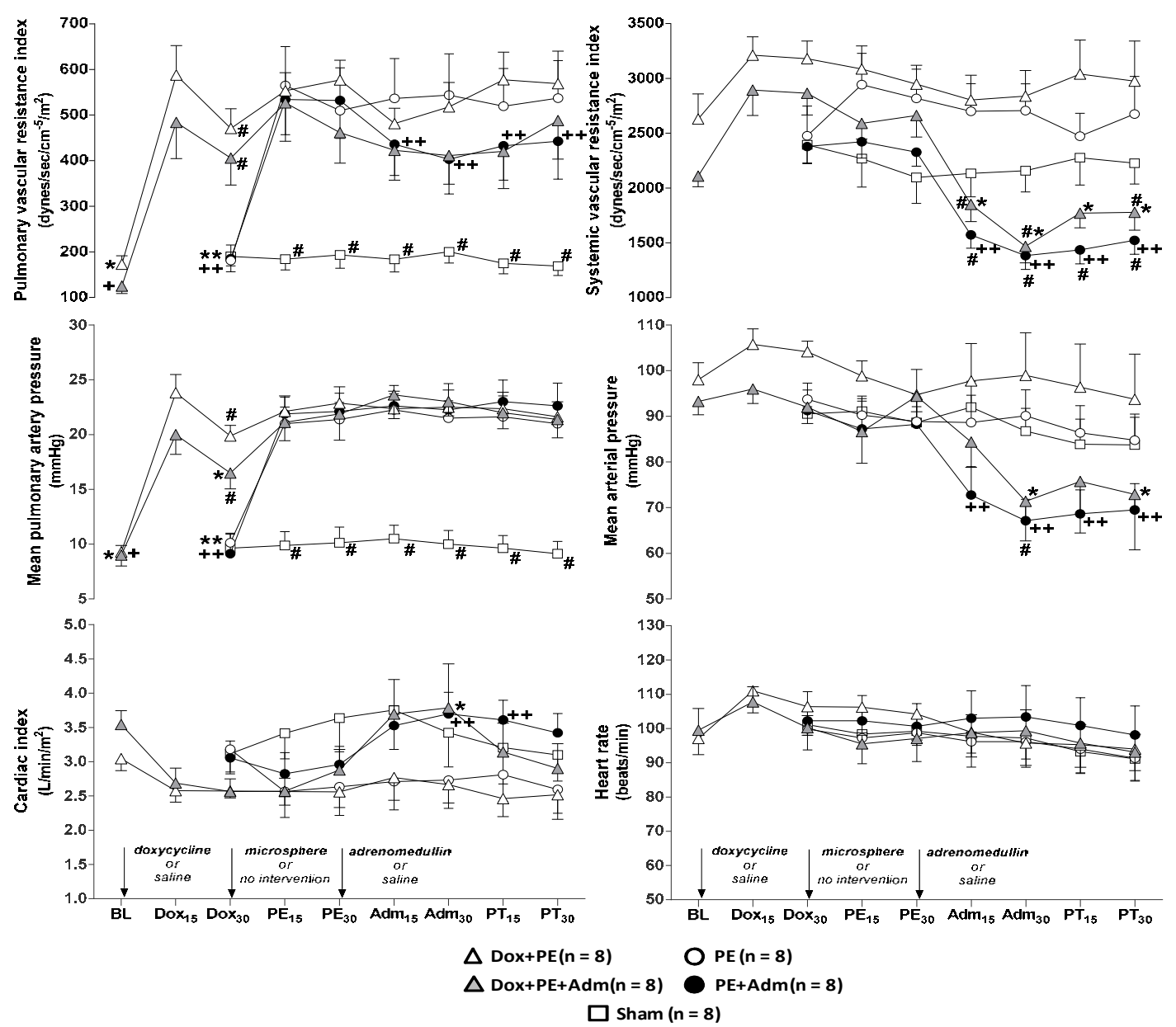

+ Significant difference $(P<0.05)$ from $\mathrm{PE}_{30}\left(\mathrm{Dox}+\mathrm{PE}\right.$ group); ${ }^{*}$ Significant difference from $\mathrm{PE}_{30}$ (Dox $+\mathrm{PE}+\mathrm{Adm}$ group);** Significant difference from $\mathrm{PE}$ ( $\mathrm{PE}$ Group); ++ Significant difference from $\mathrm{PE}_{30}(\mathrm{PE}+\mathrm{Adm}$ Group); \#Significant difference from $\mathrm{PE}$ group.

Figure 1. Hemodynamic variables (mean \pm SEM) recorded in anesthetized sheep that received i.v. doxycycline $(10 \mathrm{mg} / \mathrm{kg}) 30 \mathrm{minutes}$ before induction of pulmonary embolism with microspheres and 30 minutes later were treated with physiological saline or adrenomedullin $(50 \mathrm{ng} / \mathrm{kg} / \mathrm{min}$, during $30 \mathrm{~min})$ in the Dox $+\mathrm{PE}$ and Dox $+\mathrm{PE}+\mathrm{Adm}$ groups, respectively $(\mathrm{n}=8 \mathrm{per}$ group). Data were recorded at baseline $(\mathrm{BL})$; after $15 \mathrm{~min}\left(\mathrm{Dox}_{15}\right)$ and $30 \mathrm{~min}\left(\mathrm{Dox}_{30}\right)$ of doxycycline administration; after 15 min $\left(\mathrm{PE}_{15}\right)$ and 30 min $\left(\mathrm{PE}_{30}\right)$ of microsphere-induced pulmonary embolism; and after $15 \mathrm{~min}\left(\mathrm{Adm}_{15}\right)$ and $30 \mathrm{~min}\left(\mathrm{Adm}_{30}\right)$ of adrenomedullin or saline infusion, and $15 \mathrm{~min}\left(\mathrm{PT}_{15}\right)$ and 30 min $\left(\mathrm{PT}_{30}\right)$ after the end of adrenomedullin or saline infusion. Data from a previous study performed in anesthetized sheep not treated with doxycycline is presented for comparison (Lagos-Carvajal et al., 2015). Pulmonary embolism was induced by microspheres and 30 minutes later animals were treated with physiological saline or adrenomedullin (same dose regimen) in the PE and PE + Adm groups, respectively. Anesthetized sheep that did not undergo any intervention (Sham group) were included for comparison ( $\mathrm{n}=8$ per group). 
Table 1. Arterial carbon dioxide partial pressure $\left(\mathrm{PaCO}_{2}\right)$ and arterial oxygen partial pressure $\left(\mathrm{PaO}_{2}\right)$ at recorded in anesthetized sheep that received i.v. doxycycline $(10 \mathrm{mg} / \mathrm{kg}) 30$ minutes before induction of pulmonary embolism with microspheres and 30 minutes later were treated with physiological saline or adrenomedullin (50 $\mathrm{ng} / \mathrm{kg} / \mathrm{min}$, during $30 \mathrm{~min})$ in the Dox $+\mathrm{PE}$

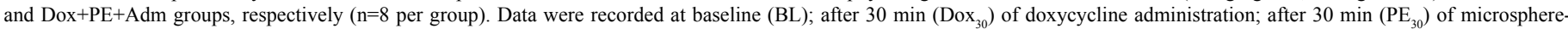
induced pulmonary embolism; after $30 \mathrm{~min}\left(\mathrm{Adm}_{30}\right)$ of adrenomedullin or saline infusion, and $30 \mathrm{~min}\left(\mathrm{PT}_{30}\right)$ after the end of adrenomedullin or saline infusion. Data from a previous study performed in anesthetized sheep not treated with doxycycline is presented for comparison [11]. Pulmonary embolism was induced by microspheres and 30 minutes later animals were treated with physiological saline or adrenomedullin (same dose regimen) in the PE and PE+Adm groups, respectively. Anesthetized sheep that did not undergo any intervention (Sham group) were included for comparison ( $\mathrm{n}=8$ per group)

\begin{tabular}{|c|c|c|c|c|c|c|}
\hline \multirow[t]{2}{*}{ Parameter } & \multirow[t]{2}{*}{ Group } & \multicolumn{5}{|c|}{ Time point } \\
\hline & & BL & Dox $_{30}$ & $\mathrm{PE}_{30}$ & $\mathbf{A d m}_{30}$ & $\mathbf{P T}_{30}$ \\
\hline \multirow{5}{*}{$\begin{array}{l}\mathbf{P a C O}_{2} \\
(\mathrm{mmHg})\end{array}$} & Dox + PE & $41 \pm 1$ & $38 \pm 1^{+}$ & $44 \pm 1$ & $40 \pm 1^{+}$ & $42 \pm 1$ \\
\hline & Dox+PE+Adm & $40 \pm 1^{*}$ & $42 \pm 1$ & $44 \pm 1$ & $43 \pm 1$ & $43 \pm 1$ \\
\hline & $\mathrm{PE}$ & - & $42 \pm 1$ & $43 \pm 2$ & $43 \pm 2$ & $41 \pm 2$ \\
\hline & PE+Adm & - & $42 \pm 1$ & $41 \pm 2$ & $39 \pm 2$ & $41 \pm 2$ \\
\hline & Sham & - & $43 \pm 1$ & $42 \pm 1$ & $41 \pm 1$ & $40 \pm 1$ \\
\hline \multirow{5}{*}{$\begin{array}{l}\mathbf{P a O}_{2} \\
(\mathrm{mmHg})\end{array}$} & Dox + PE & $423 \pm 26^{+}$ & $234 \pm 66^{+\#}$ & $92 \pm 11$ & $117 \pm 27$ & $109 \pm 26$ \\
\hline & Dox+PE+Adm & $428 \pm 15^{*}$ & $149 \pm 35^{\#}$ & $97 \pm 22$ & $140 \pm 38$ & $133 \pm 34$ \\
\hline & PE & - & $390 \pm 38^{* k *}$ & $171 \pm 33$ & $185 \pm 33$ & $165 \pm 23$ \\
\hline & $\mathrm{PE}+\mathrm{Adm}$ & - & $411 \pm 30^{++}$ & $262 \pm 49$ & $270 \pm 49$ & $253 \pm 45$ \\
\hline & Sham & - & $446 \pm 24$ & $434 \pm 31^{\#}$ & $449 \pm 19^{\#}$ & $441 \pm 16^{\#}$ \\
\hline
\end{tabular}

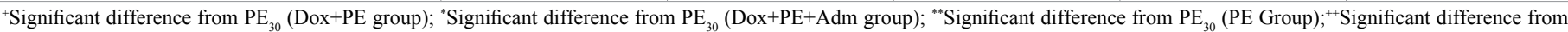
$\mathrm{PE}_{30}$ (PE+Adm Group); "Significant difference from PE group

artery pressure and cardiac index values recorded after microsphere injection and treatment with adrenomedullin in comparison with values recorded in embolized controls (PE group) (Figure 1).

Doxycycline injection alone did not alter systemic vascular resistance index and mean arterial pressure. Adrenomedullin administration in Dox $+\mathrm{PE}+\mathrm{Adm}$ and $\mathrm{PE}+\mathrm{Adm}$ groups induced significant decreases in systemic vascular resistance index from the $\mathrm{PE}_{30}$ time point. This response was accompanied by significant decreases in mean arterial pressure from $\mathrm{PE}_{30}$ in both groups, except for the $\mathrm{Adm}_{15}$ and $\mathrm{PT}_{15}$ time points in the Dox+PE+Adm group. Systemic vascular resistance index values recorded after adrenomedullin administration in Dox $+\mathrm{PE}+\mathrm{Adm}$ and $\mathrm{PE}+\mathrm{Adm}$ groups were significantly lower than values recorded in the $\mathrm{PE}$ group (except for the $\mathrm{PT}_{15}$ time point in the $\mathrm{Dox}+\mathrm{PE}+\mathrm{Adm}$ group). Mean arterial pressure values were significantly lower in the $\mathrm{PE}+\mathrm{Adm}$ group than in the PE group only at the $\mathrm{Adm}_{30}$ time point (Figure 1).

Mean $\mathrm{PaCO}_{2}$ values were maintained within physiological limits (35 to $45 \mathrm{mmHg}$ ). Small, but statistically significant decreases in $\mathrm{PaCO}_{2}$ were recorded at some time points in comparison to the $\mathrm{PE}_{30}$ time point in the Dox + PE group $\left(\operatorname{Dox}_{30}\right.$ and $\left.\mathrm{Adm}_{30}\right)$ and the Dox $+\mathrm{PE}+\mathrm{Adm}$ group (BL).

The $\mathrm{PaO}_{2}$ recorded $30 \mathrm{~min}$ after doxycycline injection $\left(\right.$ Dox $\left._{30}\right)$ in Dox $+\mathrm{PE}$ and Dox $+\mathrm{PE}+\mathrm{Adm}$ groups was significantly higher in comparison to same time point recorded in the PE group (Table 1). In the Dox $+\mathrm{PE}$ group, $\mathrm{PaO}_{2}$ was significantly higher at $\mathrm{BL}$ and at $\mathrm{Dox}_{30}$ time points in comparison to the $\mathrm{PE}_{30}$ time point. In the Dox+PE+Adm group, $\mathrm{PaO}_{2}$ was higher than $\mathrm{PE}_{30}$ only at $\mathrm{BL}$. The $\mathrm{PaO}_{2}$ was significantly lower in the $\mathrm{PE}$ group after microsphere injection in comparison to the corresponding time points in the Sham group. After microsphere injection, no significant differences were observed in $\mathrm{PaO}_{2}$ between all other embolized groups and the PE group. Heart rate did not show time related changes and did not differ among five experimental groups throughout the observational period (Figure 1).

\section{Discussion}

The main findings of the present study are the combined administration of doxycycline and adrenomedullin is not advantageous compared with adrenomedullin alone, thus suggesting that adrenomedullin counteracted the pulmonary vasoconstriction, reducing the pulmonary vascular resistance and improving the cardiac index, with moderate systemic effects during APE. These results are similar to those previously reported in sheep and humans showing that adrenomedullin induced both pulmonary vasodilation and inotropic positive effect after pulmonary hypertension [7,9]. Therefore, we suggest that the pulmonary vasoconstriction was counteracting by the adrenomedullin and it may help in the therapy of the acute hemodynamic disorder after APE.

Importantly, the suddenly impairment of cardiac output secondary APE, resulting from increased right ventricular afterload imposed by the hypertensive pulmonary circulation, may be responsible by the high incidence of death after APE [3]. In this concern, the significant increases in cardiac index induced by adrenomedullin after APE reported here represent an advantageous action for adrenomedullin in relation to other drugs tested in APE, which are able to attenuate APEinduced pulmonary hypertension by $25 \%$, but not improve cardiac index [22,27]

Although we have not evaluated cAMP levels in the present study, the hemodynamic effects may have been caused by this second messenger, mediating the vasodilatory and positive inotropic responses to adrenomedullin infusion [7-9,11,14,28,29].

We observed no advantageous effect of doxycycline combined with adrenomedullin, neither improving pulmonary vasodilatory nor cardiac index during APE. In fact, although the aim of the present study was not assess the effects of doxycycline many hours after APE, doxycycline produced no changes during early stages (90 min) after APE (Dox+PE group), as previously reported [22,23]. Thus, the absence of attenuation of APE-induced pulmonary hypertension with doxycycline could be related to the period of experimental protocol (90 min of monitoring after the induction of APE) used in this study, i.e., our observational period did not last long enough to evidence such effect, as previously reported that beneficial hemodynamic effects of MMP inhibition with doxycycline were only observed 2 hours after APE was induced [22,23]. Accordingly, an inflammatory response with an early influx of neutrophils and macrophages within the pulmonary artery's wall showed up only 3 hours after pulmonary embolism in rats [30]. So, the latency necessary to these inflammatory 
cells can release granules containing large amounts of MMPs (specially the MMP type 9, MMP-9) requests at least 2 or 3 hours after APE is installed. These suggestions may explain the beneficial effects of MMP inhibition with doxycycline have found in previous studies [22,23], but not here. Therefore, our results suggest that combining of doxycycline with adrenomedullin failed to produce synergic effects and is not an appropriated approach in the therapy, at least in the first hour soon after the APE-induced pulmonary hypertension is installed.

The increases in pulmonary vascular resistance index and mean pulmonary artery pressure values (before embolization in the Dox ${ }_{15}$ and $\operatorname{Dox}_{30}$ time points) observed with doxycycline alone are not related to doxycycline, because the same dose of this drug used here (but it was diluted in saline) produced no deleterious cardiovascular effects when administered intravenously to non-embolized animals $[17,22,23]$. Supporting our findings, previous studies may explain these apparently conflicting results, which related to the vehicle used to dilution of doxycycline (propylene glycol, the same used here), causing transient increases (peak response) in pulmonary arterial pressure in sheep [31] and fatalities in horses [32]. Importantly, the animals treated with doxycycline also showed decreases in pulmonary oxygenation here, which has not been previously reported $[17,22,23]$. Since animals were breathing an inspired oxygen fraction $>0.9$, the decrease in $\mathrm{PaO}_{2}$ observed in the present study could be attributed to an increase in intrapulmonary shunt (greater percentage of cardiac output towards to non-aerated lung areas). Atelectasis develops during anesthesia in sheep consequently leading to an increase intrapulmonary shunt fraction and oxygenation impairment [33]. Therefore, the decreases in $\mathrm{PaO}_{2}$ recorded after doxycycline might have been attributed drugs' vehicle (propylene glycol)-induced vasoconstriction in ventilated lung regions leading to the deviation of a fraction of blood flow towards atelectatic lung areas or to vehicles induced pulmonary edema increasing intrapulmonary shunt $[31,34]$.

There are little information regarding to the hemodynamic effects of intravenous infusion of doxycycline [17,22-24, 32], thus, it should be considered that the vehicle used to dilution of doxycycline must be adequately replaced $[31,32]$ or other routes to the administration of doxycycline, such as by via oral [35] must be used to avoid these disadvantageous effects. However, although the mechanisms leading to these conflicting results with doxycycline (an non-specific MMP inhibitor) are not clear at present, the possible therapeutic effects of selective MMP inhibitors should be further examined in APE setting [23], considering the important role played by MMPs hours after the onset of APE.

The present study has some limitations that should be taken into consideration. For example, patients with APE are often managed several hours after the onset of symptoms. Therefore, the very early injection of doxycycline or adrenomedullin would be impossible. Additionally, although adrenomedullin produced beneficial hemodynamic effects after APE (clearly decreased the pulmonary vascular resistance and increased the cardiac index), the sheep model of APE used in the present study (PE group) was not hemodynamically unstable, thus, the moderate systemic vasodilator effect with adrenomedullin could be a reason for concern in patients with massive pulmonary embolism, because the hypotension observed under these circumstances could be aggravated by this peptide. Therefore, adrenomedullin should be used carefully in patients hemodynamically unstable with APE and the concomitant use of vasopressor drugs should be considered to provide hemodynamic stability in hypotensive patients with APE that receive adrenomedullin.
Therefore, we conclude that intravenous administration of doxycycline neither affects APE-induced pulmonary hypertension nor improves the beneficial hemodynamic effects of adrenomedullin. Thus, the combined administration of doxycycline and adrenomedullin is not advantageous compared with adrenomedullin alone, which produced significant increases in cardiac index and decreases in pulmonary vascular resistance, thus, suggesting that adrenomedullin counteracted the pulmonary vasoconstriction and it may be interesting in the therapy of the acute hemodynamic disarrangement of APE.

\section{Acknowledgments}

The authors thank "Fundacao de Amparo a Pesquisa do Estado de Sao Paulo" (FAPESP, grant number 2012/12.291-7)” for the financial support. There are no known conflicts of interest.

\section{References}

1. Stratmann G, Gregory GA (2003) Neurogenic and humoral vasoconstriction in acute pulmonary thromboembolism. Anesth Analg 97: 341-354. [Crossref]

2. Wood KE (2011) Major pulmonary embolism. Crit Care Clin 27: 885-906. [Crossref]

3. Sanchez O, Trinquart L, Colombet I, Durieux P, Huisman MV, et al. (2008) Prognostic value of right ventricular dysfunction in patients with haemodynamically stable pulmonary embolism: a systematic review. Eur Heart J 29: 1569-1577. [Crossref]

4. Penaloza A, Roy PM, Kline J (2012) Risk stratification and treatment strategy of pulmonary embolism. Curr Opin Crit Care 18: 318-325. [Crossref]

5. Smulders YM (2001) Contribution of pulmonary vasoconstriction to haemodynamic instability after acute pulmonary embolism. Implications for treatment? Neth $\mathrm{J} \mathrm{Med}$ 58: 241-247.

6. Smulders YM (2000) Pathophysiology and treatment of haemodynamic instability in acute pulmonary embolism: the pivotal role of pulmonary vasoconstriction. Cardiovasc Res 48: 23-33. [Crossref]

7. Ertmer C, Morelli A, Rehberg S, Lange M, Hucklenbruch C, et al. (2007) Exogenous adrenomedullin prevents and reverses hypodynamic circulation and pulmonary hypertension in ovine endotoxaemia. Br J Anaesth 99: 830-836.

8. Nagaya N, Nishikimi T, Uematsu M, Satoh T, Oya H, et al. (2000) Haemodynamic and hormonal effects of adrenomedullin in patients with pulmonary hypertension. Heart 84: 653-658. [Crossref]

9. Nagaya N, Satoh T, Nishikimi T, Uematsu M, Furuichi S, et al. (2000) Hemodynamic, renal, and hormonal effects of adrenomedullin infusion in patients with congestive heart failure. Circulation 101: 498-503.

10. Nagaya N, Miyatake K, Kyotani S, Nishikimi T, Nakanishi N, et al. (2003) Pulmonary vasodilator response to adrenomedullin in patients with pulmonary hypertension. Hypertens Res 26: S141-146. [Crossref]

11. Lagos-Carvajal AP, Teixeira-Neto FJ, Becerra-Velásquez DR, Diniz MS, Klein AV, et al. (2015) Adrenomedullin induces pulmonar vasodilation but does not attenuate pulmonary hypertension in a sheep modelo of acute pulmonary embolism. Life Sci 139: $139-144$

12. Westphal M, Booke M, Dinh-Xuan AT (2004) Adrenomedullin: a smart road from pheochromocytoma to treatment of pulmonary hypertension. Eur Respir J 24: 518-520. [Crossref]

13. Nishikimi T, Horio T, Yoshihara F, Nagaya N, Matsuo H, et al. (1998) Effect of adrenomedullin on cAMP and cGMP levels in rat cardiac myocytes and nonmyocytes. Eur J Pharmacol 353: 337-344. [Crossref]

14. Rademaker MT, Charles CJ, Lewis LK, Yandle TG, Cooper GJ, et al. (1997) Beneficial hemodynamic and renal effects of adrenomedullin in an ovine model of heart failure. Circulation 96: 1983-1990. [Crossref]

15. Martínez A, Oh HR, Unsworth EJ, Bregonzio C, Saavedra JM, et al. (2004) Matrix metalloproteinase-2 cleavage of adrenomedullin produces a vasoconstrictor out of a vasodilator. Biochem J 383. [Crossref]

16. Nascimento RA, Mendes G, Possomato-Vieira JS, Gonçalves-Rizzi VH, Kushima H, et al. (2014) Metalloproteinase Inhibition Protects against Reductions in Circulating Adrenomedullin during Lead-induced Acute Hypertension. Basic Clin Pharmacol Toxicol 116: 508-515. 
17. Fortuna GM, Figueiredo-Lopes L, Dias-Junior CA, Gerlach RF, Tanus-Santos JE (2007) A role for matrix metalloproteinase-9 in the hemodynamic changes following acute pulmonary embolism. Int J Cardiol 114: 22-27. [Crossref]

18. Mühl D, Ghosh S, Uzuelli JA, Lantos J, Tanus-Santos JE (2010) Increases in circulating matrix metalloproteinase-9 levels following fibrinolysis for acute pulmonary embolism. Thromb Res 2010; 125: 549-553.

19. Cau SB, Barato RC, Celes MR, Muniz JJ, Rossi MA, et al. (2013) Doxycycline prevents acute pulmonary embolism-induced mortality and right ventricular deformation in rats. Cardiovasc Drugs Ther 27: 259-267.

20. Neto-Neves EM, Kiss T, Muhl D, Tanus-Santos JE (2013) Matrix metalloproteinases as drug targets in acute pulmonary embolism. Curr Drug Targets 14: 344-352. [Crossref]

21. Ali MA, Cho WJ, Hudson B, Kassiri Z, Granzier H, et al. (2010) Titin is a target of matrix metalloproteinase-2: implications in myocardial ischemia/reperfusion injury. Circulation 122: 2039-2047. [Crossref]

22. Neto-Neves EM, Dias-Junior CA, Rizzi E, Castro MM, Sonego F, et al. (2011) Metalloproteinase inhibition protects against cardiomyocyte injury during experimental acute pulmonar thromboembolism. Cri Care Med 39: 349-356.

23. Neto-Neves EM, Sousa-Santos O, Ferraz KC, Rizzi E, Ceron CS, et al. (2013) Matrix metalloproteinase inhibition attenuates right ventricular dysfunction and improves responses to dobutamine during acute pulmonary thromboembolism. $J \mathrm{Cell} \mathrm{Mol} \mathrm{Med}$ 17: $1588-1597$.

24. Ferraz KC, Sousa-Santos O, Neto-Neves EM, Rizzi E, Muniz JJ, et al. (2013) Recombinant human matrix metalloproteinase-2 impairs cardiovascular $\beta$-adrenergic responses. Basic Clin Pharmacol Toxicol 112: 103-109.

25. Velásquez DR, Teixeira-Neto FJ, Lagos-Carvajal AP, Steim-Diniz M, Rodríguez NC, et al. (2015) Effects of different inspired oxygen fractions on sildenafil-induced pulmonary anti-hypertensive effects in a sheep model of acute pulmonary embolism. Life Sci 127: 26-31.
26. Neto-Neves EM, Dias-Junior CA, Uzuelli JA, Pereira RP, Spiller F, et al. (2011) Sildenafil improves the beneficial hemodynamic effects exerted by atorvastatin during acute pulmonary thromboembolism. Eur J Pharmacol 670: 554-560.

27. Dias-Junior CA, Neto-Neves EM, Montenegro MF, Tanus-Santos JE (2010) Hemodynamic effects of inducible nitric oxide synthase inhibition combined with sildenafil during acute pulmonary embolism. Nitric Oxide 23: 284-288.

28. Szokodi I, Kinnunen P, Ruskoaho H (1996) Inotropic effect of adrenomedullin in the isolated perfused rat heart. Acta Physiol Scand 156: 151-152. [Crossref]

29. Szokodi I, Kinnunen P, Tavi P, Weckström M, Tóth M, et al. (1998) Evidence for cAMP-independent mechanisms mediating the effects of adrenomedullin, a new inotropic peptide. Circulation 97: 1062-1070. [Crossref]

30. Eagleton MJ, Henke PK, Luke CE, Hawley AE, Bedi A, et al. (2002) Southern Association for Vascular Surgery William J. von Leibig Award. Inflammation and intimal hyperplasia associated with experimental pulmonary embolism. J Vasc Surg 36: 581-588. [Crossref]

31. Quinn DA, Robinson D, Hales CA (1990) Intravenous injection of propylene glycol causes pulmonary hypertension in sheep. J Appl Physiol 68: 1415-1420. [Crossref]

32. Riond JL, Riviere JE, Duckett WM, Atkins CE, Jernigan AD, et al. (1992) Cardiovascular effects and fatalities associated with intravenous administration of doxycycline to horses and ponies. Equine Vet $J$ 24: 41-45. [Crossref]

33. Hedenstierna G, Lundquist H, Lundh B, Tokics L, Strandberg A, et al. (1989) Pulmonary densities during anaesthesia. An experimental study on lung morphology and gas exchange. Eur Respir J 2: 528-535.

34. Pearl RG, Finn JC (1990) Hemodynamic effects of diltiazem during vasoconstrictor pulmonary hypertension in sheep. Anesth Analg 71: 493-497. [Crossref]

35. Tynan BE, Papich MG, Kerl ME, Cohn LA (2015) Pharmacokinetics of minocycline in domestic cats. J Feline Med Surg. [Crossref]

Copyright: $(02016$ Rocha TLA. This is an open-access article distributed under the terms of the Creative Commons Attribution License, which permits unrestricted use, distribution, and reproduction in any medium, provided the original author and source are credited. 